DOI 10.15290/cnisk.2018.01.04.08

DOC. DR LUBOU KOZIK

orcid.org/0000-0003-1243-1046

Białoruski Uniwersytet Państwowy

\title{
„Bielaruskaja Rabotnitsa i Syalyanka” \\ („Białoruska Robotnica i Chłopka”) i formowanie \\ ideału kobiety sowieckiej w Białoruskiej \\ Socjalistycznej Sowieckiej Republice (1924-1939)
}

\section{Streszczenie}

W BSSR jednym ze środków formowania świadomości socjalistycznej u kobiet było czasopismo „Bielaruskaja Rabotnitsa i Syalyanka” („Białoruska Robotnica i Chłopka”), które powstało w 1924 r. (od jesieni 1931 r. „Rabotnitsa i Kalhasnica Bielarusi” [„Robotnica i Kołchoźniczka Białorusi”]). Zadaniem redakcji pisma - Wydziału Kobiecego Komitetu Centralnego Komunistycznej Partii (bolszewików) Białorusi - było rozpowszechnienie wpływu partii komunistycznej na szerokie warstwy kobiet w środowisku robotniczym i chłopskim oraz podniesienie ich poziomu kulturalno-politycznego poprzez tłumaczenie im zadań stojacych przed partia i władza sowiecka.

Kształtowanie ideału kobiety sowieckiej na łamach czasopisma „Białoruska Robotnica i Chłopka”/„Robotnica i Kołchoźniczka Białorusi” odbywało się głównie w ramach programu dotyczącego aktywności społecznej partii. Celem była zmiana statusu i roli kobiety w rodzinie oraz jej zaangażowanie w realizację zadań partii w dziedzinach politycznej, gospodarczej, społecznej i kulturalnej.

Słowa kluczowe: BSSR, propaganda, socjalizm, „Białoruska Robotnica i Chłopka”, „Robotnica i Kołchoźniczka Białorusi”, ideał kobiety sowieckiej 


\title{
"BIELARUSKAJA RABOTNITSA I SYALYANKA" (BYELORUSSIAN WORKER AND PEASANT WOMAN) AND THE FORMATION OF THE IDEAL OF A SOVIET WOMAN IN THE BYELORUSSIAN SOVIET SOCIALIST REPUBLIC (1924-1939)
}

\begin{abstract}
In the BSSR, one of the means forming socialist awareness in women was the "Bielaruskaja Rabotnitsa i Syalyanka" magazine (Byelorussian Worker and Peasant Woman), which was established in 1924 (since the autumn of 1931 "Rabotnitsa and Kalhasnica Byelarusi"). The task of the editorial office - Women's Department of the Central Committee of the Communist Party (bolsheviks) of Byelorussia - was to disseminate the influence of the communist party among broad masses of women in working and rural communities as well as to raise their cultural and political awareness by explaining the tasks of the Party and the Soviet authorities.

The shaping of the ideal of a Soviet woman in the "Bielaruskaja Rabotnitsa i Syalyanka" / "Rabotnitsa and Kalhasnica Byelarusi" magazine took place mainly as part of the social activity of the Party. The aim was to change the status and the role of women in the family and their involvement in the implementation of the Party's ideas in the political, economic, social and cultural fields.
\end{abstract}

Keywords: BSSR, propaganda, socialism, "Byelorussian Worker and Peasant Woman", "Worker and Kalhasnica of Belarus", the ideal of a Soviet woman

Dojściu bolszewików do władzy w Imperium Rosyjskim i w państwach powstałych po jego rozpadzie towarzyszył rozpad funkcjonujacych wcześniej instytucji i norm życia publicznego, politycznego i społecznego. Bolszewicy zbudowali własne instytucje władzy państwowej oraz określili zasady funkcjonowania życia publicznego. Po stłumieniu oporu opozycji władza sowiecka rozpoczęła realizację projektu kształtowania „nowego człowieka”, którego celem miało być budowanie socjalistycznego ustroju.

Proponowany przez bolszewików program przekształceń miał poparcie części obywateli Białorusi, istotna jednak przeszkoda w jego wdrażaniu był wysoki odsetek analfabetów wśród miejscowej ludności. W związku $z$ tym jednym $z$ najważniejszych zadań władzy sowieckiej 
w Białoruskiej Socjalistycznej Sowieckiej Republice (BSSR) stała się likwidacja analfabetyzmu. Zakładano, że jej integralną częścią będzie propaganda teorii marksistowsko-leninowskiej i rozpowszechnienie w społeczeństwie idei socjalistycznych. Ważne miejsce w realizacji tego zadania przyznawano sowieckim i republikańskim periodykom, które oddziaływały zarówno na wszystkie warstwy społeczeństwa, jak i na pewne grupy. Przykładem czasopisma $z$ wąskiej grupy docelowej - kobiet - była „Bielaruskaja Rabotnitsa i Syalyanka” („Białoruska Robotnica i Chłopka”).

Po przewrocie październikowym w 1917 r. w sytuacji kobiet w byłym już Imperium Rosyjskim zaszły znaczące zmiany. Dekret Rady Komisarzy Ludowych z 18 grudnia 1917 r. ogłosił równość kobiet i mężczyzn. Jak na owe czasy była to rzeczywiście idea rewolucyjna. Białoruś miała jednak swoją specyfikę polegająca na tym, że większość ludności stanowili mieszkańcy wsi, gdzie status społeczny kobiety wiejskiej w tradycyjnym społeczeństwie był niski. Kobiety nie mogły brać udziału w zebraniach wiejskich, nie mogły więc też (z rzadkimi wyjątkami) wyrażać swoich sądów ${ }^{1}$. Prawo głosu mieli wyłącznie mężczyźni.

Zmianę dotychczasowej sytuacji kobiet powierzono tzw. wydziałom kobiecym utworzonym w 1917 r. na I Wszechrosyjskim Zjeździe Robotnic i Chłopek ${ }^{2}$. Przed Wydziałem Kobiecym KC KP(b)B i podległymi mu jednostkami postawiono dwa zadania - rozciagniecie wpływu partii komunistycznej na szerokie warstwy kobiet ze środowisk robotniczych i chłopskich w celu włączenia ich do realizacji przedsięwzięć władzy sowieckiej oraz podniesienie ich poziomu kulturalno-politycznego poprzez tłumaczenie im zadań stojących przed partią i władzą sowiecką ${ }^{3}$. Jednym ze środków służących realizacji tych zadań stało się czasopismo „Białoruska Robotnica i Chłopka”. Decyzję o jego utworzeniu i kolportażu podjał KC KP(b)B na podstawie uchwały XIII Zjazdu RKP(b) o wzmocnieniu pracy periodyków dla robotnic i chłopek ${ }^{4}$.

Na Białorusi wydawanie czasopisma powierzono Wydziałowi Kobiecemu KC KP(b)B. Pierwszy numer ukazał się w rocznicę rewolucji październikowej, wszechbiałoruskiego zjazdu działaczek społecznych

1 I.W. Łaurynouskaja, Hramadski status syalyanki Bielarusi u pierszaj treci XX st., „Wiesci BDPU" seria 2, 2010, nr 2, s. 19-20.

2 Ibidem, s. 20.

3 Narodowe Archiwum Republiki Białoruś (dalej: NARB), f. 4п., op. 1, d. 1841, k. 13.

4 NARB, f. 4ח, op. 1, d. 1845, k. 91. 
i utworzenia zebrań delegatek ${ }^{5}$. Było to w listopadzie 1924 r. Periodyczność pisma wahała się od jednego do trzech numerów w miesiącu. Pod wpływem zmian społeczno-gospodarczych i politycznych w BSSR jesienia 1931 r. nazwę czasopisma zmieniono na „Robotnica i Kołchoźniczka Bia-

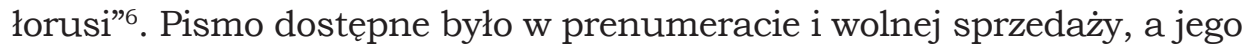
nakład wahał się od 3 do 18,5 tys. egzemplarzy ${ }^{7}$.

Pierwotnie planowano, że w czasopiśmie będą następujacce elementy: „artykuły przewodnie”, opowiadania i wiersze, publikacje o ZSSR, sytuacja za granica, życie zawodowe, życie i praca robotnic i chłopek, matka i dziecko, ruch dziecięcy, ochrona zdrowia, nauka i wiedza, rolnictwo, co trzeba czytać, korespondencja z czytelnikami, skrzynka pocztowa ${ }^{8}$. Przegląd treści pokazuje, że w latach 1924-1939 działy te pojawiały się $z$ większą lub mniejszą częstotliwością. Oprócz tego ukazywały się artykuły o świętach państwowych, $z$ poradami prawnymi, promujace zdrowy styl życia, o robótkach ręcznych, przepisy kulinarne, „strona wojenna" i inne. Wiele publikacji ukazywało sie jako reakcja na polityczne, społeczne, gospodarcze i kulturowe zmiany, które zachodziły w BSSR/ ZSSR.

Wydawca czasopisma - Wydział Kobiecy KC KP(b)B, a później KC $\mathrm{KP}(\mathrm{b}) \mathrm{B}$ - wkładał wiele wysiłku w sprawę zaangażowania kobiet w budownictwo socjalizmu, choć praca w tym kierunku szła dość ciężko. Kierowniczka Wydziału Kobiecego M. Muratawa zauważała, że po ustanowieniu władzy sowieckiej jej wydział

musiał zorganizować opóźnioną w rozwoju, zacofaną robotnicę i chłopkę i udowodnić jej, że jest ona pełnoprawnym obywatelem państwa sowieckiego i jako taka powinna nauczyć się rządzić państwem, brać aktywny udział w socjalistycznym budownictwie, że nie musi być niczyja poddana.

I dodawała:

\footnotetext{
NARB, f. 4ח, op. 1, d. 1823, k. 15, 17; Ibidem, f. 4п, op. 1, d. 1845, k. 182.

6 Na nowym etapie, nowyja zadaczy, „Rabotnitsa i Kalhasnica Bielarusi” (dalej: RiKB) 1931, nr 28, s. 1. W latach 1941-1995 pismo wychodziło pod nazwa „Rabotnitsa i Syalyanka” („Robotnica i Chłopka”), a od 1995 r. znane jest pod tytułem „Alesia”.

7 Rost tyraża żurnała za dziesiać hod, RiKB 1934, nr 21, s. 12-13. W następnych latach nakład wahał się w granicach 7-13 tys. egzemplarzy.

8 NARB, f. 4ח, op. 1, d. 1845, k. 91.
} 
Ale nie tak to łatwo pokonać dawne zawężenie umysłu, udowodnić wczorajszej niewolnicy, że dzisiaj ona jest gospodynia swojej sytuacji i musi sama zarządzać swoim życiem9

Przez dłuższy czas czasopismo walczyło o zdobycie zaufania czytelniczek. Wydział Kobiecy wielokrotnie zwracał uwage na konieczność szerokiego rozpowszechniania pisma, organizowanie prenumeraty przez aktywistki, obecność czasopisma w świetlicach, a także zwiększenie liczby korespondentek $z$ miasta i wsi. W styczniu 1925 r. Wydział Kobiecy zaznaczał, że dla wzrostu popularności wydania wśród kobiet wiejskich trzeba

pisać o chłopkach, które przeszły na lepszą formę użytkowania gruntów, o chłopkach niewierzacych, które walczą z zabobonami, o likwidacji analfabetyzmu wśród nich, o tym, jak dziewczyny wstępują do komsomołu, jak zorganizowane oddziały pionierskie, jak chłopka wstępuje do partii, o jej autorytecie wśród ludności i tak dalej ${ }^{10}$.

Od samego początku czasopismo propagowało idee socjalistyczne, a jednocześnie kształtowało ideał kobiety sowieckiej. W każdym numerze przewijała się myśl o tym, że winne one aktywnie pomagać partii komunistycznej $\mathrm{w}$ realizacji postawionych przez nią zadań ${ }^{11}$. Miało się to przejawiać w udziale kobiet w zarządzaniu państwem i działalności w partii, organizacjach gospodarczych, zawodowych i spółdzielczych. W zwiazku z tym w publikacjach zwracano uwage na konieczność podniesienia poziomu edukacji robotnic i kobiet wiejskich, wydajności i jakości ich pracy, poprawy warunków kulturalno-bytowych, działalność na rzecz wzmocnienia obronności kraju itp. ${ }^{12} \mathrm{~W}$ zależności od rozwoju sytuacji politycznej w BSSR zmieniały się akcenty w publikacjach, szcze-

\footnotetext{
9 NARB, f. 4ח, op. 1, d. 1198, k. 123.

10 NARB, f. 4ח, op. 1, d. 1845 , k. 200.

$11 Z$ adozwy CK partyi da rabotnits, syalyanak i pracounych żanczyn Bielarusi, „Bielaruskaja Rabotnitsa i Syalyanka” (dalej: BRiS) 1928, nr 12, s. 5; Piać hod, BRiS 1929, nr 22, s. 1; Zah. addzieła kultury i prapahandy leninizma CK KP(b)B - Konik, Zrabić usich żanczyn swiadomymi, piśmiennymi i aktyunymi budaunikami socyjalizma, RiKB 1934, nr 21, s. 3.

12 8-je marta, BRiS 1929, nr 4, s. 1-2; Libienzon, Pabajawomu razharnuc' masawuju rabotu siarod rabotnits $i$ pracounych syalyanak, BRiS 1931, nr 13, s. 2-3.
} 
gólnie w sprawie poszukiwania przyczyn niepowodzeń na drodze socjalistycznego budownictwa ${ }^{13}$.

W społeczeństwie sowieckim propagowano ideę o prawie kobiet do udziału w życiu społecznym i politycznym kraju oraz w zarządzaniu państwem. Uważano, że przejawem takiej aktywności miał być udział w wyborach ${ }^{14}$, w pracy zjazdów delegatek ${ }^{15}$, związków zawodowych, członkostwo w partii komunistycznej itp. Stale podkreślano, że aktywistki powinny działać na rzecz internacjonalistycznego wychowania kobiet, walczyć $z$ eksponowaniem różnic narodowych, prowadzić ateistyczna propagandę, podnosić poziom kultury oraz poziom wykształcenia robotnic i chłopek, walczyć o poprawę ich warunków bytowych, brać udział w ruchu spółdzielczym, w socjalistycznym współzawodnictwie itp ${ }^{16}$. Takim apelom towarzyszyły publikacje na temat konkretnych osób - był to przykład aktywności kobiet w życiu społeczno-politycznym kraju ${ }^{17}$.

Dużą rolę we wzroście znaczenia kobiet w socjalistycznym budownictwie odgrywały obchody 8 marca jako międzynarodowego dnia kobiet $^{18}$. W tym czasie publikowano wiele materiałów o trudnej sytuacji kobiet w krajach kapitalistycznych. Razem $z$ tekstami o trudnych warunkach przetrzymywania w więzieniach kobiet zamykanych $z$ powodów politycznych kształtowano poczucie solidarności $z$ „gnębionymi rewolucjonistami"19.

Apelom o aktywny udział kobiet w życiu społecznym i politycznym BSSR/ZSSR towarzyszyły wypowiedzi o konieczności wyrównania

13 Np. Z adozwy CK partii..., op. cit., s. 5; Piac' hod..., op. cit., s. 1-2; Bajawaja prawierka partyjnych radou, RiKB 1932, nr 35/36, s. 2, okładki - 2 .

14 A. Czarwiakou, Chto za sawieckuju uładu, toj pawinien iści na wybary, BRiS 1926, nr 12 , s. 6-7.

15 S. Kriemier, K s'jezdam rabotnits $i$ kriestjanok-obszczestwiennic, BRiS 1927, nr 9, s. 1.

16 J. Pietrowa, Żenszczina w koopieracyi, BRiS 1924, nr 1, s. 41-42; I.S. Brawarnik, Czto skazało wsiebiełorusskoje sowieszczanije rabotnits-kommunistok, BRiS 1929, $\mathrm{nr} 11$, s. 3-4; Majzit, Udzieł pracounych żanczyn u sawieckim budaunictwie, RiKB 1932, nr 7, s. 12-13; Narada żanczyn - czlenau urada, RiKB 1936, nr 4, s. 13.

17 Zob. np. A. Lowaczkina, Rascie aktyu żanczyn, RiKB 1936, nr 5, s. 11; Lepszych daczok naszaj radzimy - u Wiarchouny Sawiet SSSR, RiKB 1937, nr 22, s. 12-15.

18 Pastanowa CK WKP(b) Ab miżnarodnym komunistycznym żanoczym dni „8 sakawika”, RiKB 1936, nr 5, s. 1. Zaznaczmy, że co roku w czasopiśmie pojawiały się publikacje na temat „międzynarodowego żeńskiego komunistycznego dnia” 8 marca.

19 Zob. np.: Miżnarodnaja praletarskaja salidarnasć-zaruka pieramohi suświetnaha praletaryjatu (list da rabotnits Zachodniaj Bielarusi), BRiS 1931, nr 12, s. 5; Lutuje bieły teror u faszysckaj Polszczy. Pracounyja żanczyny, dałuczajcie swoj hołas da protestu miljonau. Zbirajcie hroszy u dapamohu palitz'niawolenym, BRiS 1931, nr 24, s. 3; Alena, Uciahnuc' usich rabotnits i pracounych żanczyn u rady MOPRu, RiKB 1933, nr 14, s. 7 i n. 
pozycji chłopek i robotnic, podniesieniu poziomu kulturalnego kobiet, poszerzaniu ich wiedzy w różnych dziedzinach. W tym celu w czasopiśmie ukazywały się artykuły, w których w dostępnej formie opisywano zjawiska przyrodnicze, dawano rekomendacje, jak się zajmować rolnictwem czy organizacja porządku domowego ${ }^{20}$.

Zdaniem kierownictwa państwa wyrzeczenie się religii jako czynnika uwsteczniającego życie społeczne miało podnieść poziom kulturalny robotnic i kobiet wiejskich. $Z$ tego powodu w publikacjach najpierw w zawoalowanej formie, a później otwarcie pisano o konieczności kształtowania światopoglądu ateistycznego ${ }^{21}$. Od czasu do czasu pisano o teatrze, kinie, muzyce lub literaturze ${ }^{22}$. Były to także artykuły propagandowe, np. o życiu, działalności i twórczości Włodzimierza Lenina, Józefa Stalina i innych działaczy sowieckich.

Redakcja czasopisma nie ograniczała się do kwestii zaangażowania kobiet w życie społeczne i polityczne państwa. Dużą uwagę poświęcano pozycji kobiety w rodzinie i społeczeństwie. W publikacjach stale podkreślano, że kobieta jest pełnoprawnym członkiem społeczeństwa i dlatego $\mathrm{w}$ rodzinie ma równe prawa $z$ mężczyzna. $\mathrm{W}$ artykułach zaznaczano, że małżeństwo powinno być dobrowolne (prawo państwowe uznawało zwiazki formalne i nieformalne), mąż i żona moga żyć osobno, każdy może samodzielnie zarządzać swoją własnością, a w przypadku nieudanego małżeństwa nie stawiano przeszkód rozwodom. Wychowanie dzieci w małżeństwie i po jego rozwiąaniu uważano za obowiązek obojga rodziców ${ }^{23}$. Często w publikacjach zwracano uwagę na fakty znęcania się męża nad żoną. Opisywano przypadki, gdy mą̇̇ odchodził do innej

20 Np.: Czto my znajem o ziemle. Poczemu bywajet dien' i nocz, BRiS 1925, nr 14, s. 27-28; Ad czaho bywaje dożdż, s'nieh i hrad, BRiS 1930, nr 4, s. 4 okładki; Famina, Jak upryho$\dot{z} y c^{\prime} \dot{z} y ł l o$, RiKB 1936, nr 5, s. 4 okładki; Makawier, Jak czyscic' i aswiażac' miechawyja reczy, RiKB 1939, nr 1, s. 4 okładki i n.

${ }^{21}$ Np.: A. Krinickij, Zaczem sozywajutsia s'jezdy kriestjanok-obszczestwiennic, BRiS 1924, nr 2, s. 1-2; S. Szamardina, Dieriewienskij byt i zadaczi kriestjanki-obszczestwiennicy, BRiS 1924, nr 2, s. 2-4; Cerkwy, sinahohi, kas'cioły-pad kultaswietnyja ustanowy, BRiS 1929, nr 23, s. 5 i n.

22 „Hryszka-swinapas”. Pierszaja biełaruskaja kino-filma, BRiS 1926, nr 9, s. 27; Or, O tieatrie, BRiS 1927, nr 1, s. 18; D. Kroz, Lubou da spiewau, da muzyki, RiKB 1936, $\mathrm{nr}$ 4, s. 11 i n.

23 S. Szamardina, Siemiejno-bracznyje woprosy (Biesieda), BRiS 1925, nr 8, s. 40; Eadem, Siemiejno-bracznyje woprosy (Biesieda wtoraja), BRiS 1925, nr 10, s. 30; Trudiaszczajasia żenszczina, siemja i brak, BRiS 1926, nr 5, s. 5; Kak isprawit' zakon o brakie, siemje i opiekie, BRiS 1928, nr 10, s. 11. Poczynając od 1927 r., w czasopiśmie ukazał się cykl artykułów na temat osobliwości wychowania dzieci. 
kobiety, pozostawiając żonę i dzieci bez pomocy materialnej. Redakcja zwracała się do aktywistek $z$ apelem, aby nie pozostawały obojętne wobec takich sytuacji, zachęcano, aby ofiary wspierać moralnie, a w razie potrzeby zwracać się do odpowiednich organów państwowych i pociagnać mężczyznę do odpowiedzialności za pozostawioną rodzinę. Kształtowano wzór aktywistki, która winna brać udział zarówno w życiu państwa, społeczeństwa, jak i nieść pomoc pojedynczym ludziom. Redakcja czasopisma formowała wizerunek kobiety samodzielnej, która może walczyć o własne interesy i stawać w obronie innych.

Biorąc pod uwagę obciążenie kobiety sprawami rodzinnymi i gospodarczymi, pismo proponowało różne sposoby na jej wyzwolenie od wielu gospodarczych kłopotów w domu i drobnych kłopotów, które odciągały ja od aktywnego udziału w życiu społecznym. Proponowano organizację przedszkoli i publicznych stołówek, a w przypadku kobiet wiejskich rozwiązaniem było tworzenie kołchozów ${ }^{24}$.

Zdaniem redakcji uczestniczki socjalistycznego budownictwa winny dbać o swoje zdrowie. W czasopiśmie wyjaśniano przyczyny i skutki najbardziej rozpowszechnionych chorób i podkreślano konieczność częstych wizyt u lekarzy. Od 1926 r. zaczęły się pojawiać artykuły o pożyteczności aktywności fizycznejej, zdrowym stylu życia. Później tłumaczono także, że służy to obronności państwa, przewidywano bowiem udział kobiet w nadchodzacej wojnie ${ }^{26}$.

Jest oczywiste, że gdyby czasopismo pełniło stricte propagandowa funkcję, to nie budziłoby zainteresowania czytelniczek ${ }^{27}$. Dlatego ukazywały się też utwory literackie, których autorzy w sposób metaforyczny propagowali idee partii. Czasami zamieszczano porady praktyczne, w których opisywano wzory odzieży (damskiej, dziecięcej, męskiej), wzory do wyszywania i lekcje robienia na drutach. Choć i w tej części czasopi-

\footnotetext{
${ }_{24}$ Zob. Ł. Popowa, Doszkolnyje uczrieżdienija raskrieposzczajut rabotnits $i$ kriestjanok, BRiS 1925, nr 3, s. 38-39.

${ }^{25}$ N. Zadoryn, Fizkultura - rabotnitsy $i$ syalyancy. Czamu nieabchodna fizkultura, BRiS 1926, nr 5, s. 12; Ch. Gubko, Fizkultura ukrieplajet zdorowje, BRiS 1926, nr 5, s. 12; Poczemu polezien zimnij sport?, BRiS 1927, nr 1, s. 20 i n.

26 Np.: Z-now, Uczastije żenszcziny w buduszczej wojnie, BRiS 1927, nr 3, s. 24; Warabjowa-Roziental, Delehatki, uzmajniajcie abaronu krainy!, BRiS 1930, nr 33, s. 3; Warabjowa, Abarona krainy i pracounaja żanczyna, BRiS 1931, nr 5, s. 7; N., Udzieł pracounych żanczyn u abaronie krainy, RiKB 1932, nr 5, s. 5 i n.

27 Redakcja ciagle miała problem ze spadkiem popytu na czasopismo, więc w każdym numerze wzywała do prenumeraty i aktywnego rozpowszechniania.
} 
sma, niezwiazanej z indoktrynacja, w 1932 r. jako wzór do wyszywania portretu pojawił się Lenin z książką w ręku ${ }^{28}$, a w 1934 r. herb ZSSR ${ }^{29}$.

Zamieszczano eleganckie modele i wzorce odzieży, których jednak aktywistki partyjne nie nosiły. W publikacjach dominował przekaz mówiący, że pogoń za modą i nowym ubraniem jest przejawem mieszczańskości, którą trzeba zwalczać. Kobietom dawano radę, aby ubierały się czysto i skromnie ${ }^{30}$.

Oprócz porad $z$ zakresu mody w czasopiśmie drukowano przepisy kulinarne, np. duszone w mleku warzywa, ziemniaki w mleku, marynowany sandacz i szczupak, kiszona kapusta, sandacz w galarecie, solanka rybna, prosię w galarecie, ryba faszerowana i inne. Takie publikacje mogły tworzyć wrażenie dobrobytu i sytości społeczeństwa sowieckiego, co, jak wiadomo, nie odpowiadało rzeczywistości. Pośrednio świadcza o tym i przepisy typu ,jak wykorzystywać gotowane kości”, „resztki ziemniaków pieczonych ze śledziem". Pojawiały się także wzmianki o problemach z zaopatrzeniem ludności w żywność.

Jak widzimy, kształtowanie ideału kobiety sowieckiej na łamach czasopisma „Białoruska Robotnica i Chłopka” / „Robotnica i Kołchoźniczka Białorusi” odbywało się głównie na drodze aktywności społecznej i partyjnej, zmiany statusu i roli kobiety w rodzinie, zaangażowania $\mathrm{w}$ realizację postawionych przed czynnikami partyjnymi i państwowymi zadań w dziedzinach politycznej, gospodarczej, społecznej i kulturalnej. Prywatne życie kobiet schodziło na dalszy plan.

Gdybyśmy spróbowali zestawić zbiorowy obraz „idealnej kobiety sowieckiej", jaki formowała redakcja czasopisma, to byłby on następujący: niezależna, samodzielna kobieta, która potrafi rozwiazywać postawione przed nią zadania, aktywna działaczka społeczna, członek partii, ateistka, internacjonalistka, pomagajacca skrzywdzonym kolegom w pracy, sąsiadom, więźniom politycznym w państwach kapitalistycznych, niezależna $\mathrm{w}$ podejmowaniu decyzji.

W pracy kobieta sowiecka jest przodowniczką („stachanowka”), walczy o wydajność i dyscyplinę pracy, jest pełnoprawnym członkiem rodziny, wychowuje dzieci w duchu budownictwa socjalistycznego. Dzieci

28 Lenin (dla wyszywańnia), RiKB 1932, nr 1, s. 4 okładki.

29 Rucznaja praca, BRiS 1931, nr 5, s. 4 okładki.

30 Zob. np. dyskusje wokół opowiadania Modnisia-Modnica, BRiS 1927, nr 12, s. 8-10; Czitatieli - o rasskazie „Modnica”, BRiS 1928, nr 2, s. 23; O rasskazie „Modnica”, BRiS 1928, nr 6, s. 22. 
kobiety sowieckiej chodzą do przedszkola, sa pionierami, a następnie komsomolcami. Kobieta dba o swoje zdrowie i wyglad. Wszystko to robi z myślą o przyszłości socjalizmu.

\section{Bibliografia}

\section{Źródła archiwalne}

Narodowe Archiwum Republiki Białoruś:

Fond 4ח., wopis. 1, sprawa 1198.

Fond 4ח., wopis. 1, sprawa 1823.

Fond 4п., wopis. 1, sprawa 1841.

Fond 4ח., wopis. 1, sprawa 1845.

\section{Źródla prasowe}

8-je marta, „Bielaruskaja Rabotnitsa i Syalyanka” 1929, nr 4, s. 1-2.

Ad czaho bywaje dożdż, s'nieh i hrad, „Bielaruskaja Rabotnitsa i Syalyanka” 1930, nr 4, s. 4 okładki.

Alena, Uciahnuc' usich rabotnits i pracounych żanczyn u rady MOPRu, „Rabotnitsa i Kalhasnica Bielarusi" 1933, nr 14, s. 7.

Bajawaja prawierka partyjnych radou, „Rabotnitsa i Kalhasnica Bielarusi” 1932, nr 35/36, s. 2 okładki - 2.

Brawarnik I.S., Czto skazało wsiebiełorusskoje sowieszczanije rabotnits-kommunistok, „Bielaruskaja Rabotnitsa i Syalyanka” 1929, nr 11, s. 3-4.

Cerkwy, sinahohi, kas'cioły - pad kultaswietnyja ustanowy, „Bielaruskaja Rabotnitsa i Syalyanka" 1929, nr 23, s. 5.

Czarwiakou A., Chto za sawieckuju uładu, toj pawinien iści na wybary, „Bielaruskaja Rabotnitsa i Syalyanka" 1926, nr 12, s. 6-7.

Czitatieli - o rasskazie „Modnica”, „Bielaruskaja Rabotnitsa i Syalyanka” 1928, nr 2, s. 23.

Czto my znajem o ziemle. Poczemu bywajet dien' i nocz, „Bielaruskaja Rabotnitsa i Syalyanka" 1925, nr 14, s. 27-28.

Famina, Jak upryhożyc' żyłlo, „Rabotnitsa i Kalhasnica Biełarusi” 1936, nr 5, s. 4 okładki.

Gubko Ch., Fizkultura ukrieplajet zdorowje, „Bielaruskaja Rabotnitsa i Syalyanka" 1926, nr 5, s. 12. 
„Hryszka-swinapas”. Pierszaja biełaruskaja kino-filma, „Bielaruskaja Rabotnitsa i Syalyanka" 1926, nr 9, s. 27.

Kak isprawit' zakon o brakie, siemje i opiekie, „Bielaruskaja Rabotnitsa i Syalyanka" 1928, nr 10, s. 11.

Kriemier S., K s'jezdam rabotnits $i$ kriestjanok-obszczestwiennic, „Bielaruskaja Rabotnitsa i Syalyanka" 1927, nr 9, s. 1.

Krinickij A., Zaczem sozywajutsia s'jezdy kriestjanok-obszczestwiennic, „Bielaruskaja Rabotnitsa i Syalyanka" 1924, nr 2, s. 1-2.

Kroz D., Lubou da spiewau, da muzyki, „Rabotnitsa i Kalhasnica Bielarusi” 1936, nr 4, s. 11.

Lenin (dla wyszywañnia), „Rabotnitsa i Kalhasnica Bielarusi” 1932, nr 1, s. 4 okładki.

Lepszych daczok naszaj radzimy - u Wiarchouny Sawiet SSSR, „Rabotnitsa i Kalhasnica Bielarusi" 1937, nr 22, s. 12-15.

Libienzon, Pabajawomu razharnuc' masawuju rabotu siarod rabotnits i pracounych syalyanak, „Bielaruskaja Rabotnitsa i Syalyanka” 1931, nr 13, s. 2-3.

Lowaczkina A., Rascie aktyu żanczyn, „Rabotnitsa i Kalhasnica Bielarusi” 1936, nr 5, s. 11.

Lutuje biely teror u faszysckaj Polszczy. Pracounyja żanczyny, dałuczajcie swoj hołas da protestu miljonau. Zbirajcie hroszy u dapamohu palitz'niawolenym, „Bielaruskaja Rabotnitsa i Syalyanka” 1931, nr 24, s. 3.

Majzit, Udzieł pracounych żanczyn u sawieckim budaunictwie, „Rabotnitsa i Kalhasnica Bielarusi" 1932, nr 7, s. 12-13.

Makawier, Jak czyscic' i aswiażac' miechawyja reczy, „Rabotnitsa i Kalhasnica Bielarusi” 1939, nr 1, s. 4 okładki.

Miżnarodnaja praletarskaja salidarnasć - zaruka pieramohi suświetnaha praletaryjatu (list da rabotnits Zachodniaj Biełarusi), „Bielaruskaja Rabotnitsa i Syalyanka" 1931, nr 12, s. 5.

Modnica, „Bielaruskaja Rabotnitsa i Syalyanka” 1927, nr 12, s. 8-10.

N., Udzieł pracounych żanczyn u abaronie krainy, „Rabotnitsa i Kalhasnica Bielarusi" 1932, nr 5, s. 5.

Na nowym etapie, nowyja zadaczy, „Rabotnitsa i Kalhasnica Biełarusi” 1931, nr 28, s. 1.

Narada żanczyn - czlenau urada, „Rabotnitsa i Kalhasnica Bielarusi” 1936, nr 4, s. 13. 
O rasskazie „Modnica”, „Bielaruskaja Rabotnitsa i Syalyanka” 1928, nr 6, s. 22.

Or, O tieatrie, „Bielaruskaja Rabotnitsa i Syalyanka” 1927, nr 1, s. 18.

Pastanowa CK WKP(b) Ab miżnarodnym komunistycznym żanoczym dni „8 sakawika”, „Rabotnitsa i Kalhasnica Bielarusi” 1936, nr 5, s. 1.

Piac' hod, „Bielaruskaja Rabotnitsa i Syalyanka” 1929, nr 22, s. 1-2.

Pietrowa J., Żenszczina w koopieracyi, „Bielaruskaja Rabotnitsa i Syalyanka” 1924, nr 1, s. 41-42.

Poczemu polezien zimnij sport?, „Bielaruskaja Rabotnitsa i Syalyanka” 1927, nr 1, s. 20.

Popowa Ł., Doszkolnyje uczrieżdienija raskrieposzczajut rabotnits $i$ kriestjanok, „Bielaruskaja Rabotnitsa i Syalyanka” 1925, nr 3, s. 38-39.

Rost tyraża żurnała za dziesiać hod, „Rabotnitsa i Kalhasnica Biełarusi” 1934, nr 21, s. 12-13.

Rucznaja praca, „Bielaruskaja Rabotnitsa i Syalyanka” 1931, nr 5, s. 4 okładki.

Szamardina S., Dieriewienskij byt $i$ zadaczi kriestjanki-obszczestwiennicy, „Bielaruskaja Rabotnitsa i Syalyanka” 1924, nr 2, s. 2-4.

Szamardina S., Siemiejno-bracznyje woprosy (Biesieda), „Bielaruskaja Rabotnitsa i Syalyanka" 1925, nr 8, s. 40.

Szamardina S., Siemiejno-bracznyje woprosy (Biesieda wtoraja), „Bielaruskaja Rabotnitsa i Syalyanka" 1925, nr 10, s. 30.

Trudiaszczajasia żenszczina, siemja i brak, „Bielaruskaja Rabotnitsa i Syalyanka" 1926 , nr 5, s. 5.

Warabjowa, Abarona krainy i pracounaja żanczyna, „Bielaruskaja Rabotnitsa i Syalyanka" 1931, nr 5, s. 7.

Warabjowa-Roziental, Delehatki, uzmajniajcie abaronu krainy!, „Bielaruskaja Rabotnitsa i Syalyanka" 1930, nr 33, s. 3.

$Z$ adozwy CK partyi da rabotnits, syalyanak i pracounych żanczyn Biełarusi, „Bielaruskaja Rabotnitsa i Syalyanka” 1928, nr 12, s. 5.

Zadoryn N., Fizkultura - rabotnitsy $i$ syalyancy. Czamu nieabchodna fizkultura, „Bielaruskaja Rabotnitsa i Syalyanka” 1926, nr 5, s. 12.

Zah. addzieła kultury i prapahandy leninizma CK KP(b)B - Konik, Zrabić usich żanczyn swiadomymi, piśmiennymi i aktyunymi budaunikami socyjalizma, „Rabotnitsa i Kalhasnica Bielarusi” 1934, nr 21, s. 3. 
Z-now, Uczastije żenszcziny w buduszczej wojnie, „Bielaruskaja Rabotnitsa i Syalyanka" 1927, nr 3, s. 24.

\section{Opracowania}

Łaurynouskaja Iryna, Hramadski status syalyanki u Biełarusi u pierszaj treci XX st., „Wiesci BDPU” seria 2: Historyja, fitasofija, palitałohija, sacyjałohija, ekanomika, kulturałohija, 2010, nr 2, s. 19-22, ISSN 1818-8583. 